\title{
Dynamic hip kinematics during squatting before and after total hip arthroplasty
}

\author{
Keisuke Komiyama', Satoshi Hamai ${ }^{*}$ (D), Daisuke Hara', Satoru Ikebe ${ }^{3}$, Hidehiko Higaki ${ }^{2}$, Kensei Yoshimoto ${ }^{1}$, \\ Kyohei Shiomoto', Hirotaka Gondo², Yifeng Wang ${ }^{2}$ and Yasuharu Nakashima'
}

\begin{abstract}
Background: The difference in in vivo kinematics before and after total hip arthroplasty (THA) for the same subjects and the clearance between the liner and neck during squatting have been unclear. The purpose of the present study was to clarify (1) the changes in the in vivo kinematics between prosthetic hips and osteoarthritis hips of the same subjects and (2) the extent of the liner-to-neck clearance during squatting under weight-bearing conditions.

Methods: This study consisted of 10 patients who underwent unilateral THA for symptomatic osteoarthritis. Using a flat-panel X-ray detector, we obtained continuous radiographs during squatting. We analyzed the hip joint's movements using three-dimensional-to-two-dimensional model-to-image registration techniques. We also quantified the minimum distance at maximum flexion and extension, and the minimum angle at maximum flexion between the liner and stem neck.

Results: The maximum hip flexion angles post-THA $\left(80.7^{\circ}\right.$ [range, 69.4-98.6 ${ }^{\circ}$ ) changed significantly compared with the pre-THA values $\left(71.7^{\circ}\right.$ [range, $\left.\left.55.2^{\circ}-91.2^{\circ}\right]\right)$. The pelvic tilt angle (posterior + , anterior-) at the maximum hip flexion postTHA $\left(10.4^{\circ}\right.$ [range, $-6.7^{\circ}$ to $26.9^{\circ}$ ]) was significantly smaller than that at pre-THA $\left(16.6^{\circ}\right.$ [range, $-3^{\circ}$ to $40.3^{\circ}$ ]). The minimum anterior and posterior liner-to-neck distances averaged 10.9 and $8.0 \mathrm{~mm}$, respectively, which was a significant difference. The minimum liner-to-neck angle at maximum flexion averaged $34.7^{\circ}\left(\right.$ range, $\left.20.7^{\circ}-46.3^{\circ}\right)$. No liner-to-neck contact occurred in any of the hips.

Conclusion: THA increased the range of hip joint motion and the pelvis tilted anteriorly more after than before THA, with sufficient liner-to-neck clearance during squatting. These data may be beneficial for advising patients after THA regarding postoperative activity restrictions in daily life.
\end{abstract}

Keywords: Kinematics, Range of motion, Squatting, Total hip arthroplasty, 3D-to-2D model-to-image registration techniques

\section{Background}

Total hip arthroplasty (THA) is the best surgical procedure for patients with end-stage osteoarthritis $(\mathrm{OA})$ of the hip joint and is highly effective in relieving pain and improving function [1-3]. The clinical success of THA allows patients to resume their activities of daily living easily, and this includes squatting motions [4]. In Non-Western cultures, squatting is one of the fundamental activities of daily living and requires deep ranges of motion in flexion $[5,6]$. Due to such requirements for

\footnotetext{
* Correspondence: hamachan@ortho.med.kyushu-u.ac.jp

1 Department of Orthopedic Surgery, Graduate School of Medical Sciences, Kyushu University, 3-1-1 Maidashi, Higashi-ku, Fukuoka 812-8582, Japan Full list of author information is available at the end of the article
}

deep flexibility of the prosthetic hip, there are concerns for impingement and dislocation after THA. Therefore, the knowledge of the in vivo kinematics of the prosthetic hip associated with squatting and the clearance between the liner and neck (liner-to-neck clearance) could be beneficial for advising for patients after THA regarding postoperative activity restrictions in daily life.

Accurate evaluations of kinematics under weight-bearing conditions have been achieved using three-dimensional (3D)-to-two-dimensional (2D) model-to-image registration techniques [7-9]. Recently, these techniques have been applied to the kinematic analyses of hips affected by OA and subsequent THA procedures $[10,11]$. We previously reported that, with respect to squatting, patients with OA

(C) The Author(s). 2018 Open Access This article is distributed under the terms of the Creative Commons Attribution 4.0 International License (http://creativecommons.org/licenses/by/4.0/), which permits unrestricted use, distribution, and 
were unable to deeply flex their femurs due to limited range of motion (ROM) of the hip joints. Additionally, patients with OA tilted their pelvis more posteriorly to maintain a deeply flexed posture than did healthy subjects [10]. In prosthetic hips, Koyanagi et al. revealed that the mean maximum hip flexion $\mathrm{ROM}$ was $86.2^{\circ}$, which is smaller than the mean maximum hip flexion angle of $95.4^{\circ}$ in normal native hips $[5,12]$. However, to the best of our knowledge, no previous report has demonstrated the changes in in vivo $3 \mathrm{D}$ kinematics during squatting pre- and post-THA for the same subjects using the accurate $3 \mathrm{D}$-to-2D model-to-image registration techniques.

The purpose of the present study was to clarify (1) the changes in the in vivo kinematics between prosthetic hips and OA hips of the same subjects and (2) the extent of the liner-to-neck clearance during squatting under weight-bearing conditions.

\section{Methods}

\section{Patients}

The protocol in the current study was approved by our institutional review board. All patients provided informed consent to participate in this study. Between August 2012 and October 2015, 177 patients with 200 hips underwent primary cementless THA by two senior surgeons (Y.N. and S.H.). Among the original 177 patients, 10 of them (10 hips) met all the inclusion criteria, which were (1) unilateral THA for symptomatic OA (2) no previous surgery of the ipsilateral hip, (3) no previous surgery of the spine or other joints, (4) obtaining the informed consent prior to THA, and (5) ability to squat safely without assistance before and after THA. Demographic data of the patients are shown in Table 1 . There were 6 women and 4 men with a mean age at the time of THA of $65 \pm 8$ years (range, 55-84 years). The mean height was $156 \pm 7 \mathrm{~cm}$ (range, 148-168 cm), and the mean body mass index (BMI) was $23 \pm 4 \mathrm{~kg} / \mathrm{m}^{2}$ (range, $18-31 \mathrm{~kg} / \mathrm{m}^{2}$ ). According to the Kellgren-Lawrence scale, 2 hips were classified as grade III and 8 hips were classified as grade IV. [13] The pre- and post-THA mean Harris hip scores were $48 \pm 7$ (range, 40-57) and $95 \pm 3$ (range, 91-99), respectively. The mean post-THA follow-up was $43 \pm 11$ months (range, 23-59 months). No patient had a history of any complication after THA.

\section{Surgical procedures and implants}

All operations were performed through a posterolateral approach with repair of the posterior soft tissue [14]. The combined anteversion technique was adopted to cope with the wide range of femoral anteversion of hip dysplasia at our institution. The cup was placed according to stem anteversion so that combined anteversion ranged from $40^{\circ}$ to $60^{\circ}$ [15]. A cementless hemispherical press-fit cup, straight metaphyseal fit stem, and high cross-linked ultra-high molecular weight polyethylene liner (AMS and PerFix HA; Aeonian; Kyocera, Kyoto, Japan) were used $[16,17]$. All femoral heads were alumina ceramic, and the head sizes were $32 \mathrm{~mm}$ in 9 cases and $26 \mathrm{~mm}$ in 1 case. There are two types of rims in the Aeonian liner, one is a $15^{\circ}$ elevated rim (elevated rim liner) to prevent dislocation of the femoral head, and the other is not elevated (flat liner). Four hips used the elevated rim liners, and 6 hips used the flat liner, respectively. When using the elevated rim liner, we recorded the location on the cup where the top of the rim was placed.

The orientations of the acetabular cup and stem were measured using the postoperative computed tomography (CT) data. The cup inclination was measured as the angle of abduction using the intertear-drop line as the baseline (radiographic inclination). The cup anteversion was measured as the angle of anteversion in the sagittal plane (operative anteversion). Femoral anteversion was measured as the angle of anteversion between the prosthetic femoral neck and transepicondylar axis [18].

Table 1 Demographic data

\begin{tabular}{|c|c|c|c|c|c|c|c|c|c|c|}
\hline Patient no. & 1 & 2 & 3 & 4 & 5 & 6 & 7 & 8 & 9 & 10 \\
\hline Sex & Male & Male & Female & Female & Male & Female & Female & Female & Female & Male \\
\hline Diagnosis & $\mathrm{OA}$ & $\mathrm{DDH}$ & $\mathrm{DDH}$ & $\mathrm{DDH}$ & $\mathrm{OA}$ & $\mathrm{DDH}$ & $\mathrm{DDH}$ & $\mathrm{DDH}$ & $\mathrm{DDH}$ & $\mathrm{OA}$ \\
\hline Age at THA (years old) & 61 & 65 & 56 & 60 & 55 & 70 & 68 & 63 & 68 & 84 \\
\hline Affected side & Right & Left & Left & Left & Right & Right & Left & Right & Right & Left \\
\hline Height (cm) & 155 & 161 & 161 & 148 & 168 & 153 & 148 & 152 & 149 & 163 \\
\hline Body weight (kg) & 73 & 63 & 46 & 46 & 70 & 44 & 40 & 55 & 64 & 65 \\
\hline BMI $\left(\mathrm{kg} / \mathrm{m}^{2}\right)$ & 30.5 & 24.3 & 17.7 & 21 & 24.7 & 18.8 & 18.3 & 24 & 28.5 & 24.5 \\
\hline Preoperative HHS & 51 & 53 & 44 & 51 & 40 & 57 & 45 & 41 & 40 & 56 \\
\hline Postoperative HHS & 97 & 98 & 91 & 91 & 91 & 98 & 94 & 99 & 97 & 95 \\
\hline Follow-up period (months) & 59 & 47 & 49 & 38 & 49 & 36 & 36 & 23 & 48 & 48 \\
\hline
\end{tabular}

$O A$ osteoarthritis, DDH developmental dysplasia of the hip, THA total hip arthroplasty, BMI body mass index, HHS Harris hip score 


\section{Kinematic analysis}

We essentially followed the method in accordance with previous reports, and we partially referenced the kinematics data regarding pre-THA $[10,19]$. The $3 \mathrm{D}$ positions and orientations of the pelvis, acetabular cup, femur, and femoral stem during squatting were determined using 3D-to-2D model-to-image registration techniques. Continuous radiographic images were used to survey squatting movements using a flat-panel X-ray detector (Ultimax-I, Toshiba, Tochigi, Japan) with the following parameters: image area of $420 \mathrm{~mm} \times 420 \mathrm{~mm}$, resolution of $0.274 \mathrm{~mm} \times$ $0.274 \mathrm{~mm} /$ pixel, and frame rate of 3.5 frames/s (Fig. 1). Each subject routinely underwent CT (Aquilion, Toshiba, Tochigi, Japan) with a $512 \times 512$ image matrix, a $0.35 \times 0.35$ pixel dim, and 1-mm-slice thicknesses from the superior edge of the pelvis to just below the knee joint line. Anatomical coordinate systems of the pelvis and femur were embedded in each bone model derived from CT data according to our previous study $[10,19]$. Computer simulation was performed to generate virtual, digitally reconstructed radiographs in which the light source and the projected plane parameters were set to be identical to the actual radiographic imaging conditions. Each model silhouette was matched with the actual silhouette by translating and rotating the $3 \mathrm{D}$ model to minimize the number of unmatched pixels between the silhouettes. The orientation of the femur relative to the pelvis: hip movements, was determined using the Cardan/Euler angle system in $x-y-z$ order (flexion/extension, adduction/abduction, internal/external rotation). The maximum errors associated with tracking the position of the femur/stem relative to the pelvis/acetabular cup were $0.36 / 0.43 \mathrm{~mm}, 0.37 / 0.48 \mathrm{~mm}$, and
$0.48 \% 0.52 \%$, respectively, for in-plane translation, out-of-plane translation, and rotation, respectively $[10,19]$.

Regarding the liner-to-neck clearance, we quantified the minimum distance at maximum flexion and extension and the angle at maximum flexion between the liner and stem neck using a computer-aided design software program ([CATIA V5]; Dassault Systemes, Vélizy-Villacoublay, France) (Fig. 2) [19, 20].

\section{Statistical analysis}

All data are expressed as mean \pm standard deviation (SD) and were tested for normality using the Shapiro-Wilk test. To compare hip kinematics before and after THA in the same patient, normally distributed variables were evaluated using the paired $t$ test. Non-normally distributed variables were evaluated using the independent Wilcoxon signed-rank test. Statistical significance was defined as a $P$ value $<.05$. The statistical analyses were performed using JMP Software (Version 11; SAS Institute, Cary, NC, USA).

\section{Results}

Orientation of the components

The mean cup inclination and mean cup anteversion were $39.1 \pm 5.4^{\circ}$ (range, $30.1^{\circ}-48.0^{\circ}$ ) and $18.5 \pm 12.0^{\circ}$ (range, $4.3^{\circ}-$ $40.0^{\circ}$ ), respectively. The mean stem anteversion was $31.7 \pm$ $6.8^{\circ}$ (range, $22.0^{\circ}-42.1^{\circ}$ ), and the mean combined anteversion was $50.3 \pm 9.3^{\circ}\left(\right.$ range, $36.9^{\circ}-67.5^{\circ}$ ) (Table 2).

\section{Kinematics of the hip joint}

The maximum hip flexion angles were determined during squatting at $10 \%$ of the squat ascent cycle pre-THA, and at $15 \%$ of the squat ascent cycle post-THA,
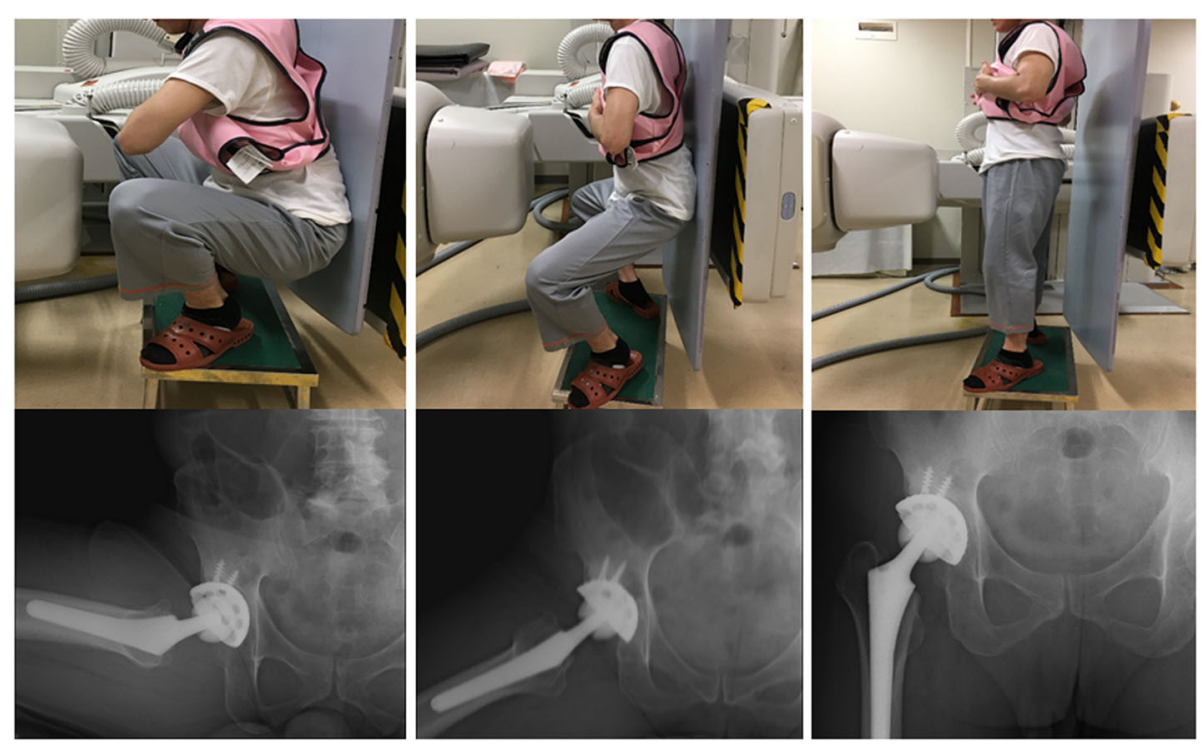

Fig. 1 The hip motions during squatting were captured as continuous X-ray images using a flat panel X-ray detector. Patients before and after total hip arthroplasty stood from a squat position with their heel down 

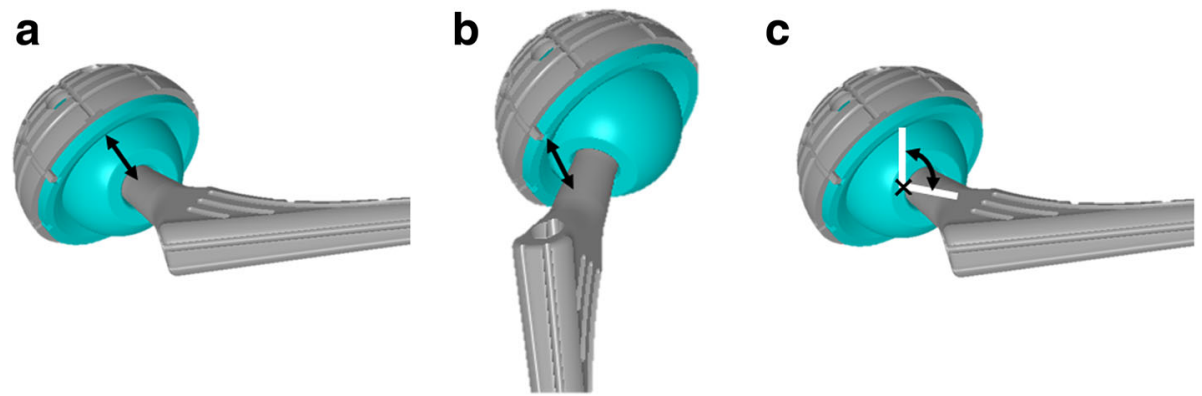

Fig. 2 The minimum distance at maximum flexion (a) at maximum extension (b), and the angle at maximum flexion (c) between the liner and stem neck

respectively (Fig. 3). The kinematics data of each patient are shown in Table 3. The maximum femoral and hip flexion angles post-THA $\left(94.9 \pm 6.8^{\circ}\right.$ [range, $85.4^{\circ}-104.6^{\circ}$ ] and 80.7 $\pm 10.0^{\circ}$ [range, $69.4^{\circ}-98.6^{\circ}$ ], respectively) changed significantly $(P=.013$ and $P=.005$, respectively) compared with the pre-THA values $\left(86.2 \pm 7.3^{\circ}\right.$ [range, $70.9^{\circ}-94.3^{\circ}$ ] and $71.7 \pm 11.9^{\circ} \quad$ [range, $55.2^{\circ}-91.2^{\circ}$ ], respectively) (Figs. 3 and 4). In the squatting position, the pelvis tilted backward and gradually tilted forward with standing. The pelvic tilt angle (posterior + , anterior-) at the maximum hip flexion post-THA $\left(10.4 \pm 10.4^{\circ}\right.$ [range, $-6.7^{\circ}$ to $26.9^{\circ}$ ] was significantly $(P=.0463)$ smaller than that at pre-THA $\left(16.6 \pm 13.3^{\circ}\right.$ [range, $-3^{\circ}$ to $40.3^{\circ}$ ]) (Fig. 5).

\section{Liner-to-neck clearance}

The liner-to-neck clearance data for the each patient are shown in Table 3. The minimum anterior and posterior liner-to-neck distances averaged $10.9 \pm 2.2 \mathrm{~mm}$ (range, $7.3-14.8 \mathrm{~mm}$ ) and $8.0 \pm 2.4 \mathrm{~mm}$ (range, $3.6-11.2 \mathrm{~mm}$ ), respectively, and the difference was significant $(P=.0143)$. The minimum liner-to-neck angle at maximum flexion averaged $34.7 \pm 7.3^{\circ}$ (range, 20.7-46.3 $3^{\circ}$. No liner-to-neck contact occurred in any of the hips during squatting.

\section{Discussion}

To our knowledge, no previous reports have demonstrated the changes in in vivo hip kinematics during squatting pre- and post-THA for the same subjects using accurate 3D-to-2D model-to-image registration techniques. The current study elucidated the dynamic hip kinematics during squatting before and after THA and quantified the liner-to-neck clearance. The maximum hip flexion significantly changed from $72^{\circ}$ pre-THA to $81^{\circ}$ post-THA, and the pelvic tilt angle at the maximum hip flexion post-THA was $10^{\circ}$, which was significantly smaller than the $17^{\circ}$ measurement pre-THA. The anterior and posterior liner-to-neck distances averaged 11 and $8 \mathrm{~mm}$, respectively, and the differences were significant. The mean minimum liner-to-neck angle was $35^{\circ}$, and there was no liner-to-neck contact during squatting in any of the hips.

A previous study found that patients with $\mathrm{OA}$ were not able to flex their femurs deeply due to limited ROM of the hip joints during squatting. They also tend to tilt their pelvises more posteriorly to maintain a deeply flexed posture than did healthy subjects [10]. The present study revealed that the maximum hip flexion was improved by approximately $9^{\circ}$. The pelvic tilt at the maximum hip flexion post-THA was significantly inclined and measured approximately $7^{\circ}$ more anteriorly than pre-THA for the same subjects. We found that THA increased the range of the femoral and hip joint motions during squatting, and the compensation to maintain deeply flexed postures was reduced. Sagittal pelvic mobility is integral in flexing the torso to maintain

Table 2 Component data

\begin{tabular}{lllllllllll}
\hline Patient no. & 1 & 2 & 3 & 4 & 5 & 6 & 7 & 8 & 9 & 10 \\
\hline Cup size $(\mathrm{mm})$ & 52 & 50 & 48 & 46 & 52 & 48 & 48 & 48 & 50 & 54 \\
Head size $(\mathrm{mm})$ & 32 & 32 & 32 & 26 & 32 & 32 & 32 & 32 & 32 & 32 \\
Polyethylene liner & Flat & Flat & Flat & Flat & Elevated & Elevated & Flat & Flat & Elevated & Elevated \\
Cup inclination $\left(^{\circ}\right)$ & 36.6 & 42 & 30.1 & 44 & 41.2 & 37.1 & 34.1 & 42.4 & 48 & 35.2 \\
Cup anteversion $\left(^{\circ}\right)$ & 4.3 & 16 & 11 & 10.1 & 26.8 & 5 & 24 & 35.3 & 38 & 14.9 \\
Stem anteversion $\left(^{\circ}\right)$ & 34.8 & 37 & 38.1 & 34 & 26.4 & 42.1 & 28.1 & 32.2 & 22.6 & 22 \\
Combined anteversion $\left(^{\circ}\right)$ & 39.1 & 53 & 49.1 & 44.1 & 53.2 & 47.1 & 52 & 67.5 & 60.6 & 36.9 \\
\hline
\end{tabular}




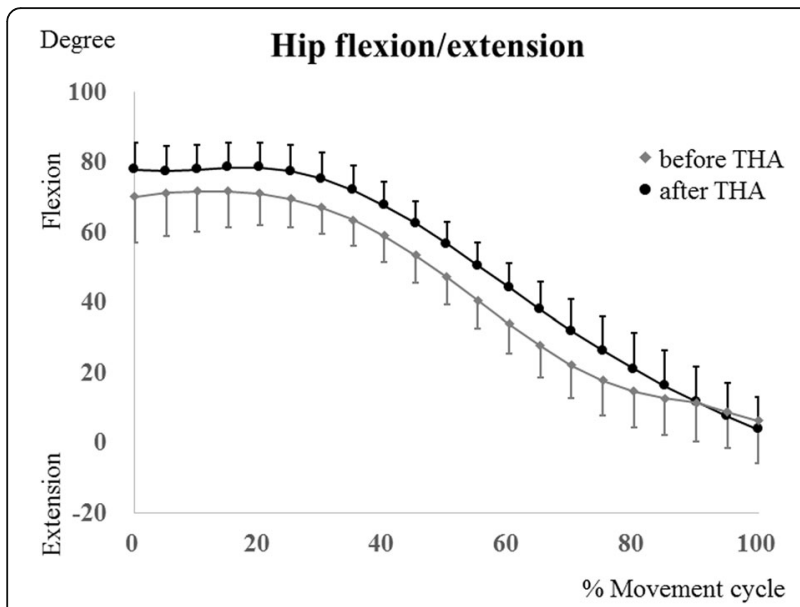

Fig. 3 The hip flexion/extension angles during squatting in patients before total hip arthroplasty (THA) (gray lines) and patients after THA (black lines). Error bars show standard deviation

balance and to allow the large hip flexion angles that are essential for deep squats [21].

It has been reported that approximately 95 to $102^{\circ}$ of maximum hip flexion occurs during squatting in healthy subjects $[5,22]$. Our study showed that the maximum hip flexion significantly changed from $72^{\circ}$ pre-THA to $81^{\circ}$ post-THA. Although THA provided increased ROM in patients with $\mathrm{OA}$, prosthetic hips were not able to recover the kinematics to the level of healthy hips. Catelli et al. reported that joint kinematics of the pelvis and hip do not return to the level of healthy hips after THA during squatting and dual-mobility implant combined with the poorer functional scores [23]. A limited range of hip flexion persisted even after THA, which might have affected postoperative functional outcomes during activities of daily living, especially those requiring deeply flexed postures.

Specific postures might include potential risks of prosthetic impingement and could cause postoperative dislocation, and polyethylene wear after THA [24, 25]. However, we found only a few reports which quantified the liner-to-neck distances while squatting. In our study, the anterior and posterior liner-to-neck distances averaged 11 and $8 \mathrm{~mm}$, respectively, and the differences were significant. Furthermore, the minimum liner-to-neck angle at maximum flexion was $21^{\circ}$. Koyanagi et al. reported that the minimum angle leading up to theoretical prosthetic impingement was more than $10^{\circ}$ [12]. Based on the analysis, we concluded that the liner-to-neck clearance during squatting after THA was sufficient in these patients.

There are several limitations in the present study. First, the number of patients in this study was small. A larger sample size with a wider variation in component position might result in greater statistical reliability and reveal correlation between implant positioning and minimum liner-to-neck clearance; this topic needs further clarification. Second, kinematic processing of radiographic measurements imparts a risk of radiation exposure. However, we believe that this represents an important data-driven approach to provide feedback on the activities of daily living specific advice for each patient. Third, this study examined only a single component design. Although the design is similar to that of many others that are currently available, the results could differ. Fourth, the sequential motions during

Table 3 Patient kinematic data

\begin{tabular}{|c|c|c|c|c|c|c|c|c|c|c|}
\hline Patient No. & 1 & 2 & 3 & 4 & 5 & 6 & 7 & 8 & 9 & 10 \\
\hline \multicolumn{11}{|l|}{ Maximum hip flexion $\left(^{\circ}\right)$} \\
\hline Pre-THA & 59.5 & 73.1 & 67.2 & 83.5 & 73.3 & 70.7 & 59.4 & 84.3 & 91.2 & 55.2 \\
\hline Post-THA & 75.6 & 73.3 & 71.6 & 90.5 & 81.3 & 87.5 & 71.2 & 87.6 & 98.6 & 69.4 \\
\hline \multicolumn{11}{|l|}{ Maximum femoral flexion $\left({ }^{\circ}\right)$} \\
\hline Pre-THA & 77.2 & 92.9 & 85.8 & 93.8 & 87 & 86.9 & 87.2 & 85.5 & 94.3 & 70.9 \\
\hline Post-THA & 96.5 & 92.1 & 91.7 & 102.1 & 86 & 92.1 & 104.6 & 85.4 & 103.1 & 95.1 \\
\hline \multicolumn{11}{|l|}{ Pelvic tilt at maximum hip flexion $\left(^{\circ}\right)$} \\
\hline Pre-THA & 40.3 & 20.6 & 15.5 & 8.1 & -3 & 18.9 & 31.2 & 2.5 & 7.6 & 23.9 \\
\hline Post-THA & 20.3 & 15.4 & 16.7 & 4.2 & 3.5 & 3.8 & 17.6 & -6.7 & 2.3 & 26.9 \\
\hline \multicolumn{11}{|l|}{ Liner-to-neck clearance } \\
\hline the minimum anterior distance $(\mathrm{mm})$ & 10 & 9.5 & 11.4 & 8.2 & 11.2 & 12.4 & 12.4 & 12.1 & 14.8 & 7.3 \\
\hline the minimum posterior distance (mm) & 10.1 & 7 & 9.9 & 8.9 & 11.2 & 7.3 & 10.1 & 5.8 & 6 & 3.6 \\
\hline the minimum angle at maximum hip flexion $\left(^{\circ}\right)$ & 30.6 & 32.6 & 35.2 & 31.8 & 31 & 34.9 & 44 & 40.1 & 46.3 & 20.7 \\
\hline
\end{tabular}

THA total hip arthroplasty

The pelvic tilt (posterior +, anterior-) angles 


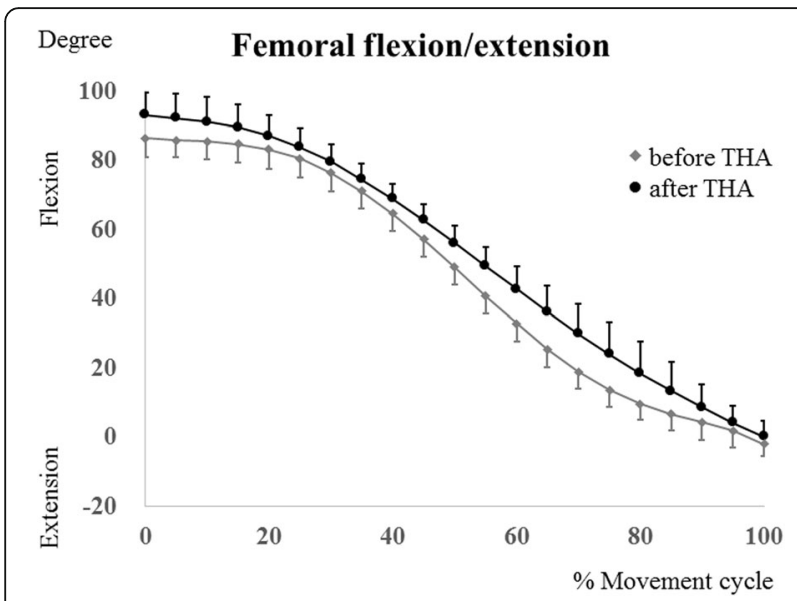

Fig. 4 The femoral flexion/extension angles during squatting in patients before total hip arthroplasty (THA) (gray lines) and patients after THA (black lines). Error bars show standard deviation squatting were collected into twice, because even the large flat-panel X-ray detector that was used in this study provided a limited field of view (FOV). It might be necessary that the development of fluoroscopy is expected to achieve quite a large FOV. Finally, the patients included in this study were all Japanese with lower BMI compared to the Caucasian average. The patients with a $\mathrm{BMI} \geq 30 \mathrm{~kg} / \mathrm{m}^{2}$ could show different kinematic data with limited maximum hip flexion angle.

\section{Conclusion}

We quantified the change in hip kinematics before and after THA and the liner-to-neck clearance while squatting

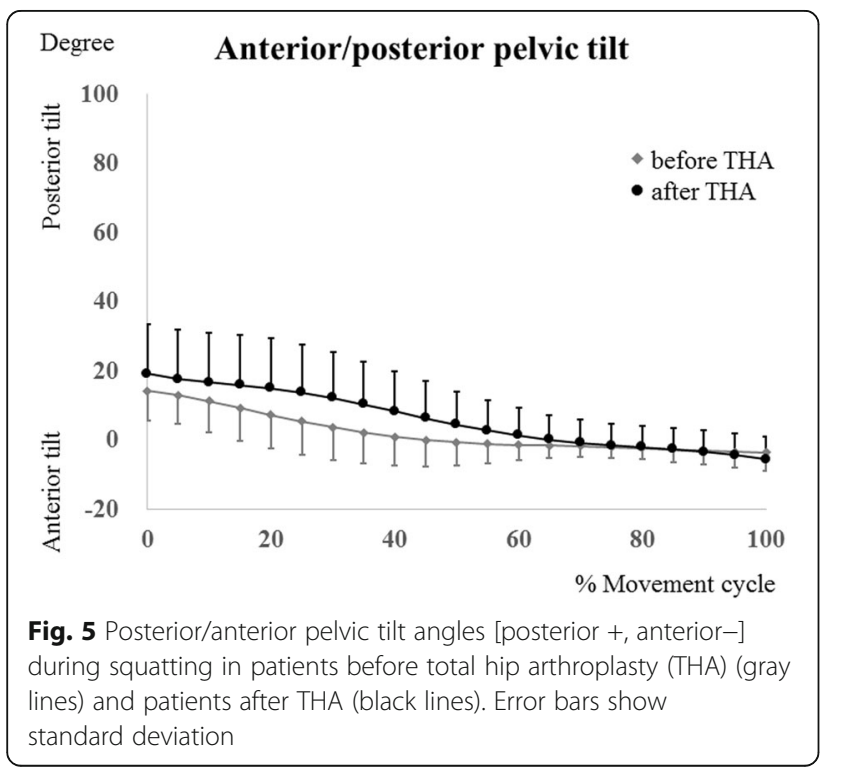

using the 3D-to-2D model-to-image registration techniques. THA increased the ranges of femoral and hip joint motion and the pelvis tilted anteriorly more after than before THA, with sufficient liner-to-neck clearance during squatting. These data may be beneficial for advising patients after THA regarding postoperative activity restrictions in daily life.

\section{Abbreviations}

2D: Two-dimensional; 3D: Three-dimensional; BMl: Body mass index; $\mathrm{CT}$ : Computed tomography; DDH: Developmental dysplasia of the hip; FOV: Field of view; HHS: Harris hip score; OA: Osteoarthritis; ROM: Range of motion; SD: Standard deviation; THA: Total hip arthroplasty

\section{Funding}

This study was supported by JSPS KAKENHI Grant No. 15 K10450 and 25870499, grant from the Japan Orthopaedics and Traumatology Foundation, Inc. (No. 263), and grant from the Nakatomi Foundation.

\section{Availability of data and materials}

The datasets supporting the conclusions of the present study are available from the corresponding author on reasonable request.

\section{Authors' contributions}

$\mathrm{KK}, \mathrm{SH}, \mathrm{DH}, \mathrm{SI}, \mathrm{HH}$, and YN contributed to the conception and design of the study. KK, SH, DH, KY, and KS performed acquisition of data. KK, SH, DH, SI, $\mathrm{HH}, \mathrm{HG}$, and $\mathrm{YW}$ conducted data analysis, and $\mathrm{KK}, \mathrm{SH}$, and $\mathrm{YN}$ contributed to data interpretation and preparation of the manuscript. All authors read and approved the final version of the manuscript.

\section{Ethics approval and consent to participate}

All procedures performed in studies involving human participants were in accordance with the ethical standards of our institution and the 1964 Helsinki Declaration and its later amendments or comparable ethical standards. This study was approved by the Institutional Review Board (IRB) of Kyushu University (IRB number 24-55). The subject was given informed consent to participate in this IRB approved study and was informed of the risk of radiation exposure required.

\section{Consent for publication}

Not applicable.

\section{Competing interests}

The authors declare that they have no competing interests.

\section{Publisher's Note}

Springer Nature remains neutral with regard to jurisdictional claims in published maps and institutional affiliations.

\section{Author details}

${ }^{1}$ Department of Orthopedic Surgery, Graduate School of Medical Sciences, Kyushu University, 3-1-1 Maidashi, Higashi-ku, Fukuoka 812-8582, Japan. ${ }^{2}$ Department of Life Science, Faculty of Life Science, Kyushu Sangyo University, 2-3-1 Matsugadai, Higashi-ku, Fukuoka 813-0004, Japan. ${ }^{3}$ Department of Creative Engineering, National Institute of Technology, Kitakyushu College, 5-20-1 Shii, Kokuraminami-ku, Kitakyushu, Fukuoka 802-0985, Japan.

Received: 22 March 2018 Accepted: 25 June 2018

Published online: 03 July 2018

\section{References}

1. Learmonth ID, Young C, Rorabeck $C$. The operation of the century: total hip replacement. Lancet. 2007;370(9597):1508-19.

2. Chang RW, Pellisier JM, Hazen GB. A cost-effectiveness analysis of total hip arthroplasty for osteoarthritis of the hip. JAMA. 1996;275(11):858-65.

3. Jacobsen S, Sonne-Holm S, Soballe K, Gebuhr P, Lund B. Hip dysplasia and osteoarthrosis: a survey of 4151 subjects from the osteoarthrosis substudy of the Copenhagen City Heart Study. Acta Orthop. 2005;76(2):149-58. 
4. Rissanen P, Aro S, Slatis P, Sintonen H, Paavolainen P. Health and quality of life before and after hip or knee arthroplasty. J Arthroplast. 1995;10(2):169-75.

5. Hemmerich A, Brown H, Smith S, Marthandam SS, Wyss UP. Hip, knee, and ankle kinematics of high range of motion activities of daily living. J Orthop Res. 2006;24(4):770-81.

6. Tang H, Du H, Tang Q, Yang D, Shao H, Zhou Y. Chinese patients' satisfaction with total hip arthroplasty: what is important and dissatisfactory? J Arthroplast. 2014;29(12):2245-50.

7. Komistek RD, Dennis DA, Mahfouz M. In vivo fluoroscopic analysis of the normal human knee. Clin Orthop Relat Res. 2003;410:69-81.

8. Hamai S, Moro-oka TA, Miura H, Shimoto T, Higaki H, Fregly BJ, Iwamoto Y, Banks SA. Knee kinematics in medial osteoarthritis during in vivo weightbearing activities. J Orthop Res. 2009;27(12):1555-61.

9. Ishimaru M, Shiraishi Y, Ikebe S, Higaki H, Hino K, Onishi Y, Miura H. Threedimensional motion analysis of the patellar component in total knee arthroplasty by the image matching method using image correlations. J Orthop Res. 2014;32(5):619-26.

10. Hara D, Nakashima Y, Hamai S, Higaki H, Ikebe S, Shimoto T, Yoshimoto K, Iwamoto Y. Dynamic hip kinematics in patients with hip osteoarthritis during weight-bearing activities. Clin Biomech. 2016;32:150-6.

11. Tsai T-Y, Li J-S, Wang S, Lin H, Malchau H, Li G, Rubash H, Kwon Y-M. A novel dual fluoroscopic imaging method for determination of THA kinematics: in-vitro and in-vivo study. J Biomech. 2013;46(7):1300-4.

12. Koyanagi J, Sakai T, Yamazaki T, Watanabe T, Akiyama K, Sugano N, Yoshikawa H, Sugamoto K. In vivo kinematic analysis of squatting after total hip arthroplasty. Clin Biomech. 2011:26(5):477-83.

13. Kellgren JH, Lawrence JS. Radiological assessment of osteo-arthrosis. Ann Rheum Dis. 1957;16(4):494-502.

14. Pellicci PM, Bostrom M, Poss R. Posterior approach to total hip replacement using enhanced posterior soft tissue repair. Clin Orthop Relat Res. 1998;355:224-8.

15. Nakashima Y, Hirata M, Akiyama M, Itokawa T, Yamamoto T, Motomura G, Ohishi M, Hamai S, Iwamoto Y. Combined anteversion technique reduced the dislocation in cementless total hip arthroplasty. Int Orthop. 2014;38(1): $27-32$.

16. Sato T, Nakashima Y, Akiyama M, Yamamoto T, Mawatari T, Itokawa T, Ohishi M, Motomura G, Hirata M, Iwamoto Y. Wear resistant performance of highly cross-linked and annealed ultra-high molecular weight polyethylene against ceramic heads in total hip arthroplasty. J Orthop Res. 2012;30(12):2031-7.

17. Nakashima Y, Sato T, Yamamoto T, Motomura G, Ohishi M, Hamai S, Akiyama M, Hirata M, Hara D, Iwamoto Y. Results at a minimum of 10 years of follow-up for AMS and PerFix HA-coated cementless total hip arthroplasty: impact of cross-linked polyethylene on implant longevity. J Orthop Sci. 2013;18(6):962-8.

18. Yoshioka Y, Siu D, Cooke TD. The anatomy and functional axes of the femur. J Bone Joint Surg Am. 1987;69(6):873-80.

19. Hara D, Nakashima Y, Hamai S, Higaki H, Ikebe S, Shimoto T, Yoshimoto K, Iwamoto Y. Dynamic hip kinematics during the golf swing after total hip arthroplasty. Am J Sports Med. 2016;44(7):1801-9.

20. Yoshimoto K, Hamai S, Higaki H, Gondoh H, Nakashima Y. Visualization of a cam-type femoroacetabular impingement while squatting using imagematching techniques: a case report. Skelet Radiol. 2017;46(9):1277-82.

21. Lamontagne M, Kennedy MJ, Beaule PE. The effect of cam FAl on hip and pelvic motion during maximum squat. Clin Orthop Relat Res. 2009;467(3): 645-50.

22. Hara D, Nakashima Y, Hamai S, Higaki H, Ikebe S, Shimoto T, Hirata M, Kanazawa M, Kohno Y, Iwamoto Y. Kinematic analysis of healthy hips during weight-bearing activities by 3D-to-2D model-to-image registration technique. Biomed Res Int. 2014;2014:457573.

23. Catelli DS, Kowalski E, Beaule PE, Lamontagne M. Does the dual-mobility hip prosthesis produce better joint kinematics during extreme hip flexion task? J Arthroplast. 2017;32(10):3206-12.

24. Shon WY, Baldini T, Peterson MG, Wright TM, Salvati EA. Impingement in total hip arthroplasty a study of retrieved acetabular components. J Arthroplasty. 2005;20(4):427-35.

25. Marchetti E, Krantz N, Berton C, Bocquet D, Fouilleron N, Migaud H, Girard J. Component impingement in total hip arthroplasty: frequency and risk factors. A continuous retrieval analysis series of 416 cup. Orthop Traumatol Surg Res. 2011;97(2):127-33.

\section{Ready to submit your research? Choose BMC and benefit from:}

- fast, convenient online submission

- thorough peer review by experienced researchers in your field

- rapid publication on acceptance

- support for research data, including large and complex data types

- gold Open Access which fosters wider collaboration and increased citations

- maximum visibility for your research: over $100 \mathrm{M}$ website views per year

At BMC, research is always in progress.

Learn more biomedcentral.com/submissions 